\title{
SISTEM PENDUKUNG KEPUTUSAN PENERIMAAN PESERTA COMPETENCE AID PROGRAM DI ASTRAGRAPHIA DENGAN METODE SAW
}

\author{
Dian Gustina $^{(1)}$, Ibnu Fauzi Meirianto ${ }^{(2)}$ \\ Universitas Persada Indonesia Y.A.I \\ dgustina@yahoo.com
}

\begin{abstract}
The process of receiving training CAP participants can be an error in determining the participants who are eligible to join in the training. This can happen because of the number of assessment criteria and participants who register, meanwhile the participants received only 10 people. The purpose and writing of this final task is to produce a decision support system of cap participant acceptance in astragraphia, which can help in determining the participants who are entitled to the training and also the acceptance decision is more grounded because it has passed the calculation stage according to the existing criteria. System development method used is System Development Life Cycle (SDLC). Starting from the stage of needs analysis, design, coding, and testing. the method for the calculation of decision support system used is Simple Additive Weigthing method $(S A W)$, because this method can distinguish different calculations between attributes cost and benefit. The results of the application test show that the functionality of the application is in accordance with what is planned and issued the expected output
\end{abstract}

Keywords : Decision support system, Simple Additive Weigthing, SDLC, Training, CAP

Abstrak
Kegiatan proses penerimaan peserta pelatihan CAP dapat terjadi kesalahan dalam
menentukan peserta yang berhak mengikuti pelatihan. Hal ini bisa terjadi karena
banyaknya kriteria penilaian dan peserta yang mendaftar, sedangakan peserta yang
diterima hanya 10 orang. Tujuan dan penulisan tugas akhir ini adalah menghasilkan
system pendukung keputusan penerimaan peserta CAP di astragraphia, yang dapat
membantu dalam menentukan peserta yang berhak mengikuti training dan juga keputusan
penerimaan lebih berdasar karena telah melewati tahap perhitungan sesuai kriteria yang
ada. Metode pengembangan system yang digunakan adalah Sistem Development Life
Cycle (SDLC). Dimulai dari tahap analisis kebutuhan, desain, pembuatan kode program,
dan pengujian. Sedangkan metode untuk unttuk perhitungan system pendukung keputusan
yang digunakan adalam metode Simple Additive Weigthing (SAW), karena metode ini
dapat membedakan perhitungan yang berbeda antara atribut cost dan benefit. Hasil
pengujian aplikasi menunjukan bahwa secara fungsional aplikasi sudah sesuai dengan apa
yang direncanakan dan mengeluarkan output yang diharapkan
Kata kunci : Sistem Pendukung Keputusan, Simple Additive Weigthing, SDLC, Pelatihan,
CAP




\section{PENDAHULUAN Latar belakang}

Teknologi telah menyentuh berbagai lini kehidupan, baik dibidang pendidikan, bisnis, medis, penjualan dan juga pelayanan jasa. Semua telah bertransfer dari tradisional ke modern, dari pencatatan di buku jurnal ke pencatatan di database, dari proses manual berubah menjadi otomatis atau memanfaatkan teknologi informasi. Dengan diubahnya proses-proses manual menjadi proses menggunakan teknologi informasi, membuat proses tersebut memiliki waktu pekerjaan yang cepat, data mudah di back-up, dan yang paling utama adalah meminimalisasi kesalahan yang dapat ditimbulkan manusia. Kesalahan dalam manusia merupakan hal yang wajar, namun menjadi tidak wajar atau menjadi penting ketika kesalahan dilakukan di proses proses penting, seperti perhitungan atau juga pengambilan keputusan. Perusahaan akan mendapat efek negative jika kesalahan terjadi pada proses yang penting. Maka dari itu sebaiknya perusahaan menerapkan teknologi informasi di sektor sektor yang rawan akan kesalahan manusia. Sehingga kesalahan dapat dicegah untuk terjadi atau diminimalisasikan sekecil mungkin.

CAP (Competence Aid Program) merupakan program peningkatan kemampuan dibidang IT, khususnya networking dan dekstop support yang ditujukan untuk mahasiswa yang sudah lulus atau di semester akhir dan diselenggarakan oleh PT Astra Graphia. Setiap periode CAP memikat banyak calon peserta untuk mengikuti program ini, namun sayangnya hanya 10 peserta yang akan diterima. Terdapat banyak kategori yang dijadikan pertimbangan dalam penerimaan peserta CAP. Banyak nya pelamar pelatihan dan banyak- nya kategori pertimbangan, tidak diimbangi dengan jumlah orang yang bertanggung jawab dalam proses penerimaan tersebut. Hanya 1 orang yang bertanggung jawab dalam proses seleksi dan penentuan peserta yang diterima.

Dengan banyaknya pelamar pelatihan, banyaknya kategori yang dijadikan bahan pertimbangan dan hanya 1 orang yang bertugas dalam menentukan peserta peserta yang berhasil diterima, membuat proses ini rawan "human error", human error yang bisa terjadi adalah ragu dalam menentukan siapa saja peserta yang berhasil diterima, karena tidak ada perankingan dalam proses manual.

Dengan melihat masalah yang sudah diuraikan diatas, akan lebih baik proses penerimanaan peserta CAP menggunakan suatu sistem yang membantu dalam pengambilan keputusan. Sistem yang akan memberikan rekomendasi nama-nama yang sebaiknya diterima menurut sistem setelah melewati tahap perhitungan dan perankingan. Alternatif dari pemecahan masalah ini adalah dengan dibuatnya "Sistem Pendukung Keputusan Penerimaan Peserta Competence Aid Program di Astra Graphia dengan Metode SAW".

\section{Rumusan Masalah}

1) Bagaimana merancang sistem pendukung keputusan penerimaan peserta training CAP di Astragraphia

2) Bagaimana menerapkan metode $S A W$ sebagai metode dalam membuat sistem pendukung keputusan di kasus ini 


\section{Batasan Masalah}

Agar pembahasan dapat dilakukan sesuai dengan apa yang diharapkan,maka batasan masalah yang diambil adalah :

1) Sistem pendukung keputusan yang dibuat menggunakan metode SAW.

2) Ruang lingkup aplikasi ini hanya untuk penerimaan peserta training CAP di Astragraphia Kramat Raya, Jakarta.

3) Sistem pendukung keputusan ini dibangun menggunakan VB.net dan database MySql.

\section{Tujuan}

Tujuan dilaksanakannya penelitian untuk membuat laporan tugas akhir ini adalah:

1) Merancang sistem yang membantu dalam menentukan peserta yang berhak mengikuti training CAP.

2) Memberikan skor berupa nilai kepada setiap pendaftar training untuk memudahkan dalam mengambil keputusan.

3) Keputusan penerimaan lebih dapat dipertanggung jawabkan karena telah melewati tahap perhitungan

\section{Metode Pengembangan Sistem}

Metode pengembangan system yang digunakan penulis untuk menyelesaikan berbagai permasalahan yang ditemukan adalah Sistem Development Life Cycle. Sedangkan model yang digunakan dalam SDLC nya ialah model waterfall dengan tahapan sebagai berikut :

1) Analisis Kebutuhan

Proses pengumpulan kebutuhan system pendukung keputusan yang akan dibangun agar dapat dipahami perangkat lunak atau system seperti apa yang dibutuhkan
2) Desain

Proses membuat database yang diperlukan, membuat tampilan desain aplikasi, menentukan menu menu yang diperlukan dari tahap analisis

3) Pembuatan Kode Program

Proses pembuatan kode program system pendukung keputusan sesuai dari tahap analisis dan desain yang telah ditentukan

4) Pengujian

Dilakukan pengujian aplikasi system pendukung keputusan yang telah dibuat.

\section{Metode Perhitungan Sistem Pendukung Keputusan}

Metode yang digunakan dalam perhitungan system pendukung keputusan yang dibuat menggunakan metode Simple Additive Weighting (SAW). Metode ini dipilih karena di metode ini dapat membedakan atribut cost dan benefit.

\section{KAJIAN PUSTAKA}

Pengertian Sistem Pendukung Keputusan

Sistem Pendukung Keputusan (SPK) adalah sistem berbasis komputer yang interaktif dalam membantu pengambil keputusan untuk memanfaatkan data dan model untuk menyelesaikan masalah (Heny Pratiwi, 2016: 4). SPK dengan didukung oleh sebuah sistem informasi berbasis komputer dapat membantu seseorang meningkatkan kinerjanya dalam pengambilan keputusan. Seorang manajer di suatu perusahaan dapat memecahkan masalah semi terstruktur, sehingga manajer dan komputer harus bekerja sama sebagai tim pemecah masalah dalam memecahkan masalah yang berada di area semi terstruktur. 


\section{Tujuan Sistem Pendukung Keputusan}

Tujuan sistem pendukung keputusan mempunyai tiga tujuan yang akan dicapai adalah (Heny Pratiwi, 2016: 7):

1) Membantu manajer membuat keputusan untuk memecahkan masalah semi terstruktur

2) Mendukung penilaian manajer bukan mencoba menggantikannya

3) Meningkatkan efektifitas pengambilan keputusaan manajer daripada efisiensinya

\section{Metode Simple Additive Weighting (SAW) \\ Metode Simpe Additive Weighting} (SAW) adalah metode penjumlahan bobot dari kinerja setiap objek objek yang berbeda dan memiliki kesempatan yang sama pada semua kriteria yang dimiliki. Metode Simple Additive Weighting memerlukan proses normalisasi matriks keputusan $(\mathrm{X})$ ke suatu skalan yang dapat dibandingkan dengan semua rating alternative yang ada (Heny Pratiwi, 2016: 136).

$$
r_{i j}=\left\{\begin{array}{l}
\frac{x_{i j}}{\operatorname{Max}_{i} x_{i j}} \\
\frac{\operatorname{Min}_{i} x_{i j}}{x_{i j}}
\end{array}\right.
$$

\section{Gambar 1 cara nilai rating ternormalisasi}

Keterangan :

rij $=$ nilai rating kinerja ternormalisasi

xij $=$ nilai atribut yang dimiliki dari setiap kriteria

Maxi $x i j=$ nilai terbesar dari setiap kriteria $i$
Mini xij $=\underset{\text { nrilai teria } \mathrm{i}}{\text { nilkecil dari setiap }}$

Benefit = jika nilai terbesar adalah terbaik

Cost $=$ jika nilai kecil adalah terbaik

Nilai preferensi untuk setiap alternative (Vi) diberikan sebagai :

$$
\mathrm{V}_{\mathrm{i}}=\sum_{\mathrm{j}=1}^{\mathrm{n}} \mathrm{w}_{\mathrm{j}} \mathrm{r}_{\mathrm{ij}}
$$

\section{Gambar 2 Cara rangking alternative}

Keterangan:

$\mathrm{Vi} \quad=$ rangking untuk setiap alternatif

$\mathrm{Wj} \quad=$ nilai bobot dari setiap kriteria

rij = nilai rating kinerja ternormalisasi

Nilai Vi yang lebih besar mengindikasikan bahwa alternative Ai lebih terpilih

Langkah - Langkah Penyelesaian Masalah

1) Menentukan kriteria-kriteria yang akan dijadikan acuan dalam pengambilan keputusan yaitu $\mathrm{Ci}$

2) Menentukan rating kecocokan setiap alternative pada setiap kriteria

3) Membuat matriks keputusan berdasarkan kriteria(ci), kemudia melakukan normalisasi matriks berdasarkan persamaan yang disesuaikan dengan jenis atribut sehingga diperoleh matriks ternormalisasi $\mathrm{R}$

4) Hasil akhir diperoleh dari proses perangkingan yaitu penjumlahan dari perkalian matriks ternormalisasi $\mathrm{R}$ dengan vector bobot sehingga diperoleh nilai terbesar yang dipilih sebagai alternative terbaik (Ai) sebagai solusi 


\section{PERANCANGAN APLIKASI}

UML adalah standarisasi bahasa pemodelan untuk pembangunan perangkat lunak yang dibangun dengan menggunakan teknik pemrograman berorientasi objek.

\section{Pemodelan Use Case}

Use Case atau Diagram Use Case merupakan pemodelan untuk kelakuan (behavior) sistem informasi yang akan dibuat. Use Case mendeskripsikan sebuah sistem interaksi antara satu atau lebih aktor dengan system informasi yang akan dibuat.

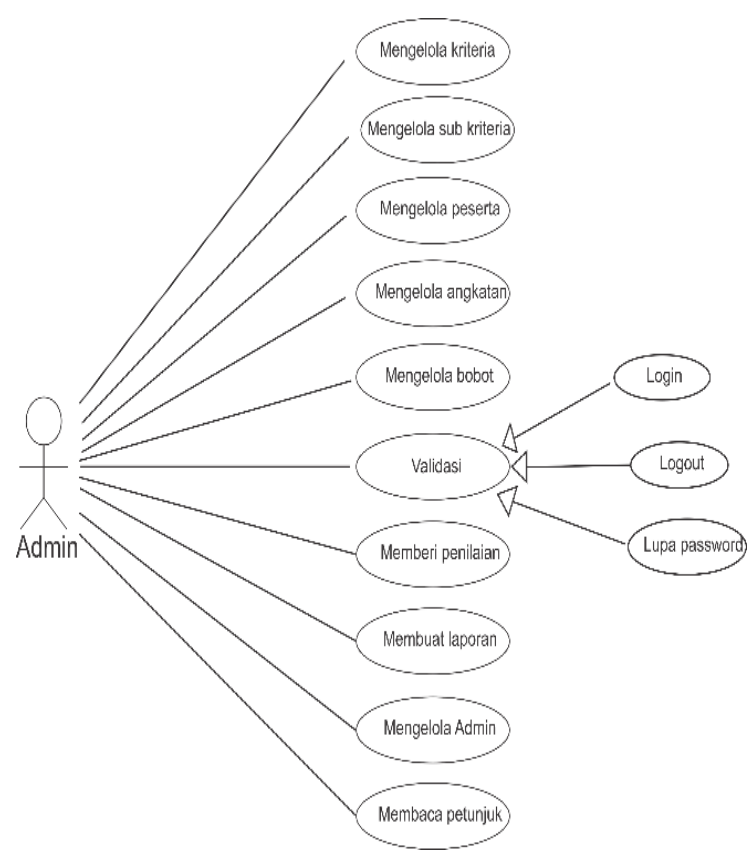

\section{Gambar 3 Use Case Diagram}

\section{Sequence Diagram}

Diagram sekuen menggambarkan kelakuan objek pada use case dengan mendeskripsikan waktu hidup objek dan message yang dikirmkan dan diterima antar objek. Untuk menggambar diagram sekuen maka harus diketahui objek objek yang terlibat dalam sebuah use case

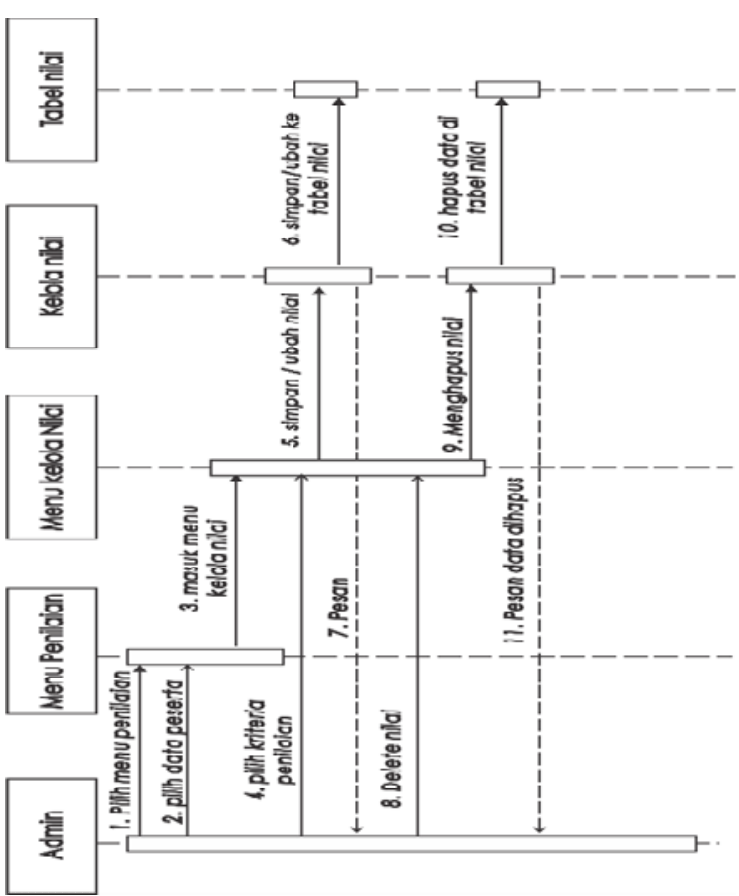

Gambar 4. S D memberi penilaian

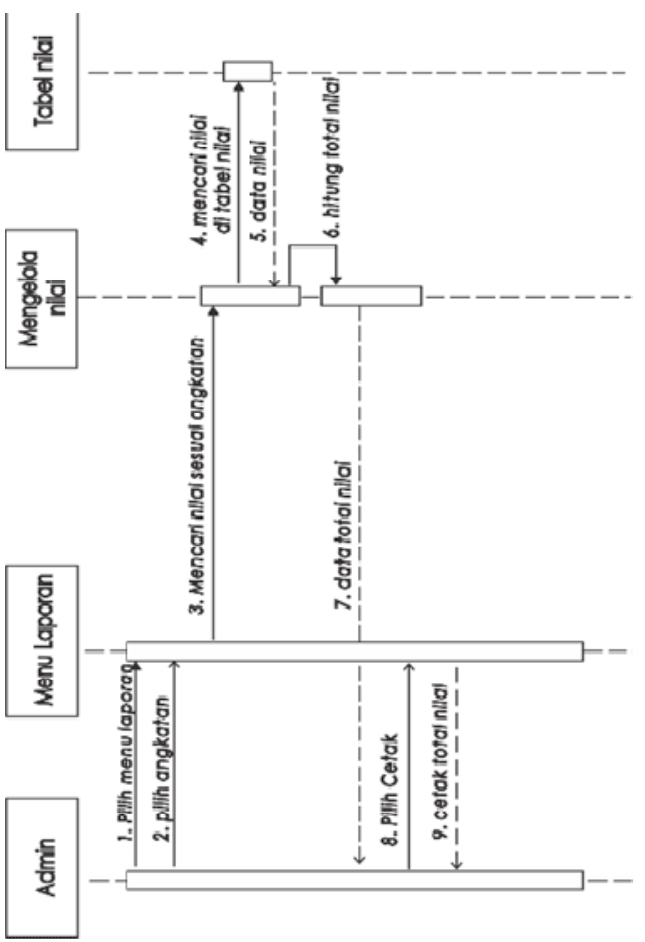

Gambar 5. S D membuat laporan 


\section{Activity Diagram}

Diagram aktivitas atau activity diagram menggambarkan workflow (aliran kerja) atau aktivitas dari sebuah sistem atau prose bisnis atau menu yang ada pada perangkat lunak

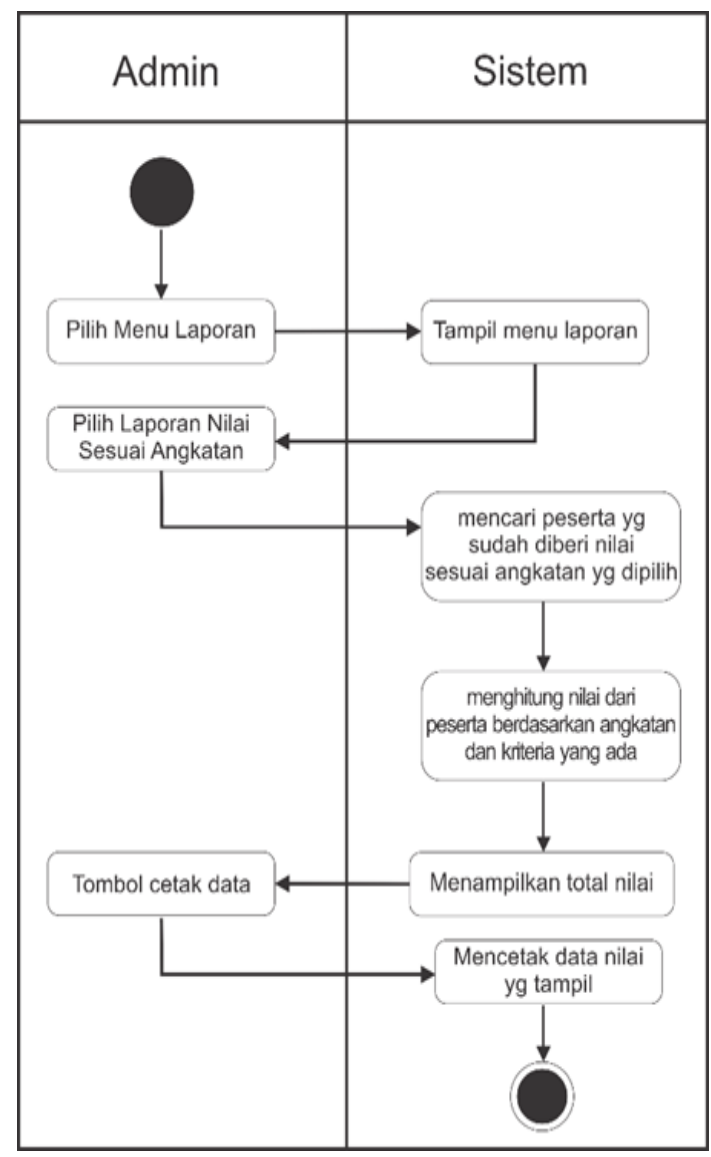

Gambar 6. A D memberi penilaian

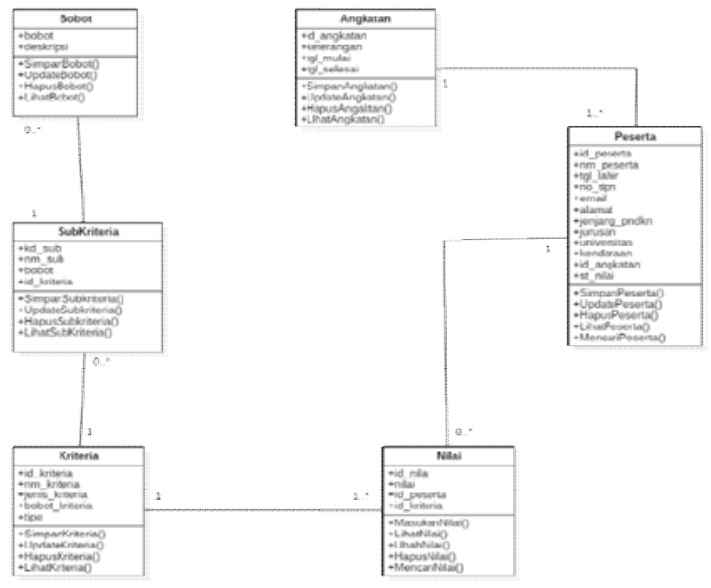

Gambar 7 A D membuat laporan

\section{Class Diagram}

Diagram kelas atau class diagram menggambarkan struktur sistem dari segi pendefinisian kelas-kelas yang akan dibuat untuk membangun sistem. Kelas memiliki apa yang disebut atribut dan metode.

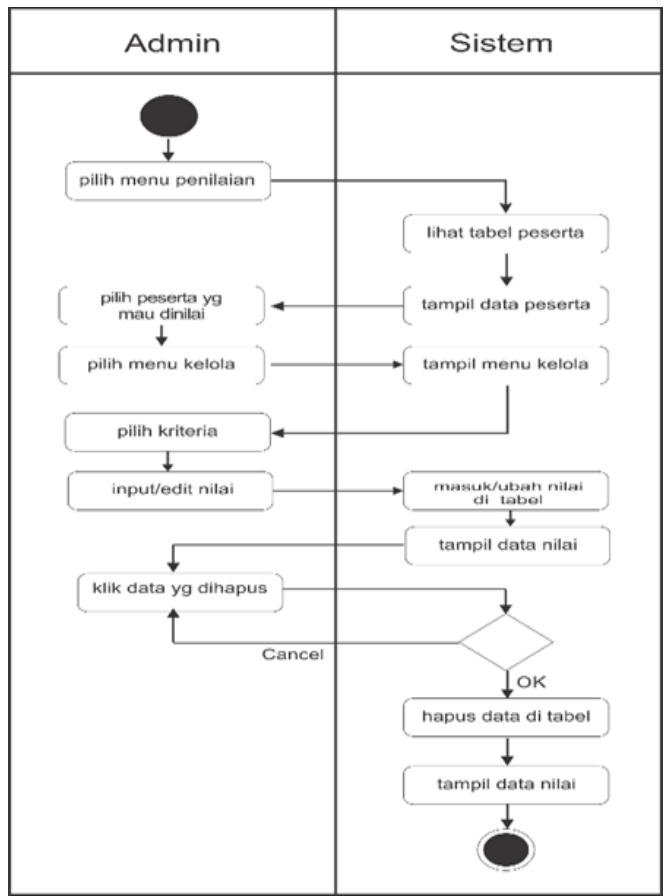

Gambar 8. Class diagram 


\section{Struktur Navigasi}

Struktur Navigasi dapat dikatakan sebagai penggambar dari hubungan atau rantai kerja dari seluruh element yang akan digunakan dalam aplikasi. Adapun navigasi pada aplikasi ini adalah sebgai berikut:

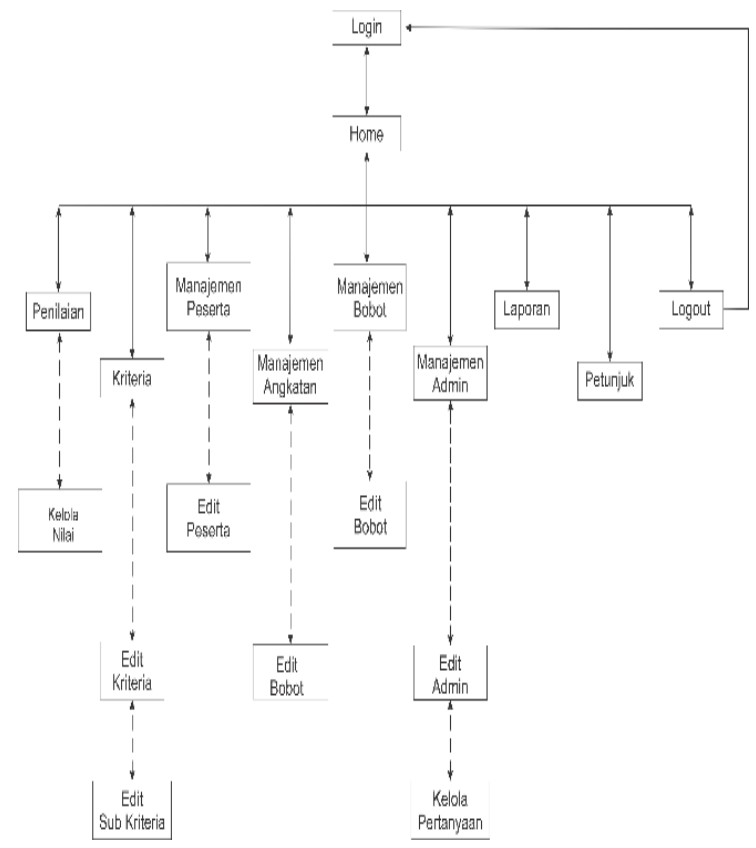

Gambar 9. Struktur navigasi

\section{IMPLEMENTASI}

Setelah melakukan konseptualisasi dan perancangan aplikasi langkah selanjutnya adalah melakukan pengumpulan bahan, pembuatan dan testing aplikasi. Pengumpulan bahan, pembuatan dan testing pada aplikasi ini terdiri dari spesifikasi kebutuhan perangkat keras, spesifikasi kebutuhan perangkat lunak, fungsi dari setiap halaman pada aplikasi disertai dengan cara pengoperasian

\section{Spesifikasi Perangkat Lunak dan Perangkat Keras}

1) Spesifikasi Perangkat Keras
a. Prosesor intel core i3-2330M 2.20Ghz
b. Hardisk 500Gb 5400RPM
c. RAM DDR3 $4 \mathrm{~Gb}$
d. Intel HD graphics 3000

2) Spesifikasi Perangkat Lunak
a. Visual Studio
b. XAMPP (digunakan Mysql nya)
c. Mysql Connector Odbc

\section{Tampilan Antarmuka Aplikasi}

Berikut ini adalah hasil dari tampilanantar muka yang sudah di rancang pada aplikasi ini yang dilakukan dengan fokus kepada fungsi masing-masing tampilan

1) Tampilan login admin

Tampilan login merupakan tampilan yang pertama kali akan dihadapi saat aplikasi inidibuka. Login dilakukan oleh admin untuk dapat masuk ke aplikasi sistem dengan memasukan username dan password

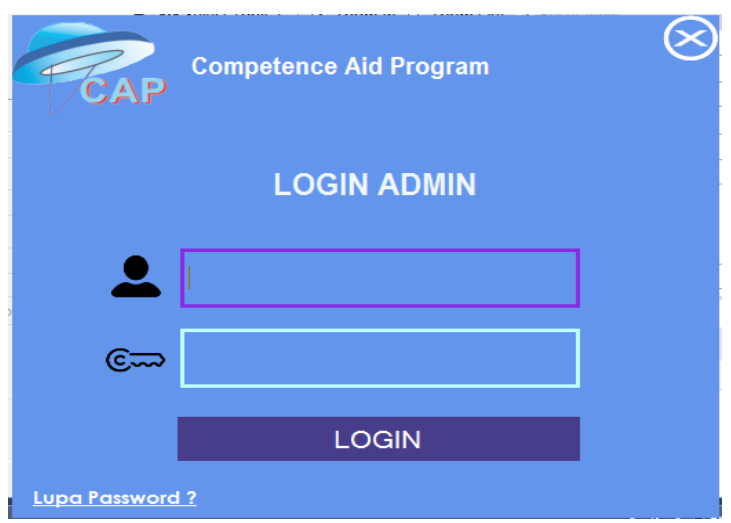

\section{Gambar 10. Tampilan Login Admin}

2) Tampilan Home

Tampilan home merupakan tampilan utama dari aplikasi setelah admin melakukan login dan login nya berhasil. 
Admin akan disajikan halaman utama Halaman home berisi beberapa informasi data dalam system

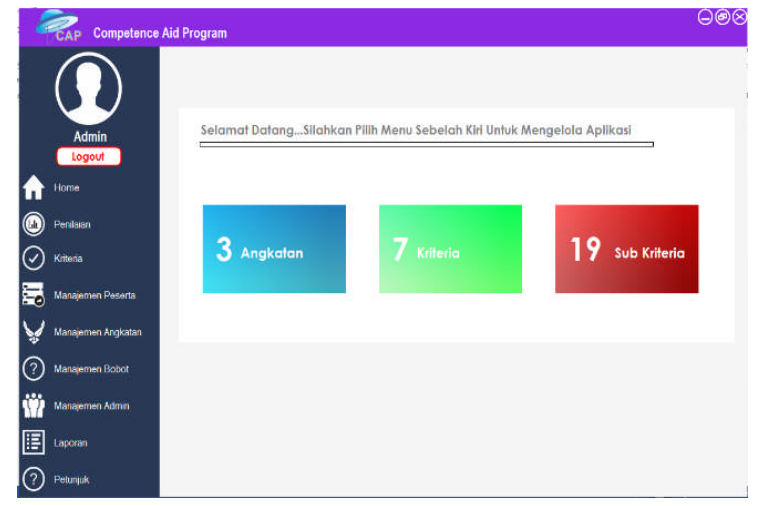

Gambar 11. Tampilan Home

3) Tampilan Menu Penilaian

Tampilan menu penilaian merupakan tampilan yang berfungsi untuk memberikan nilai kepada setiap peserta.. Di halaman ini juga terdapatcombobox untuk memilih menampilkan peserta berdasarkan angkatan yang ada.

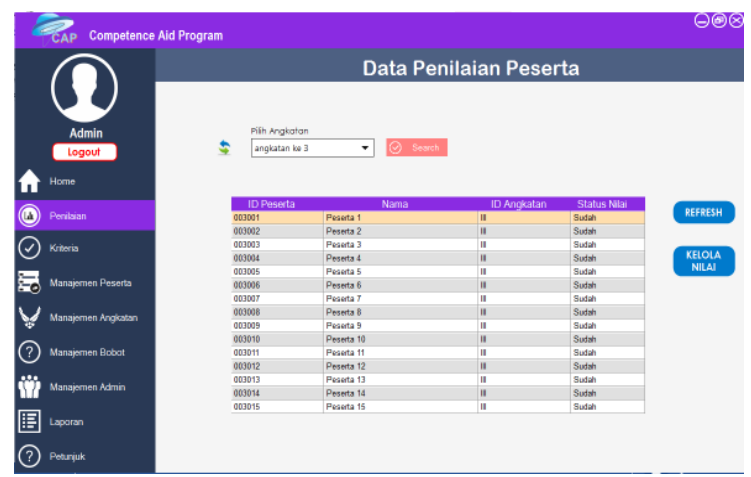

Gambar 12. Tampilan Menu Penilaian

4) Tampilan Menu Kriteria

Tampilan menu kriteria merupakan tampilan yang berisi kriteria kriteria yang telah ditentukan.Admin dapat memasukan kriteria sebanyak kebutuhan sistem yang diperlukan, namun total bobot kriteria tidak bisa melebihi nilai 100.Di menu ini juga terdapat data data sub kriteria. Sub kriteria merupakan data cabang atau anakan dari kriteria yang bertipe option.

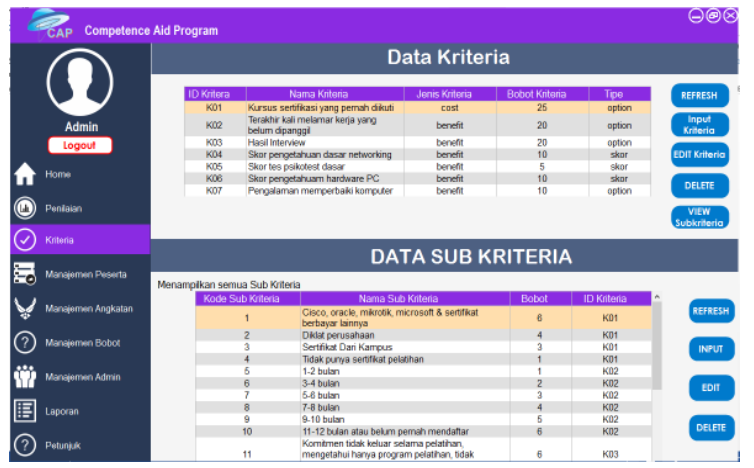

\section{Gambar 13. Tampilan Menu Kriteria}

5) Tampilan Menu Manajemen Peserta Tampilan menu peserta merupakan tampilan data data peserta, menu ini merupakan master data peserta yang berisi data data peserta dimana dalam tampilan ini admin dapat mengelola data data peserta,

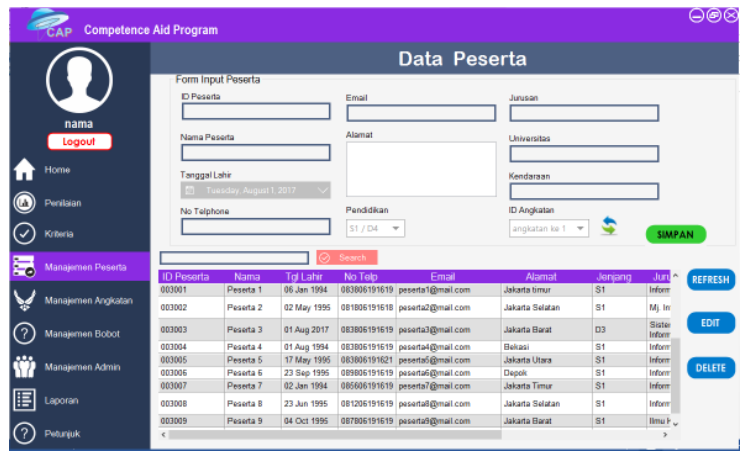

\section{Gambar 14. Tampilan Menu Manajemen Peserta}

6) Tampilan Menu Manajemen Angkatan Tampilan menu manajeman angkatan merupakan tampilan data data angkatan dari pelatihan 


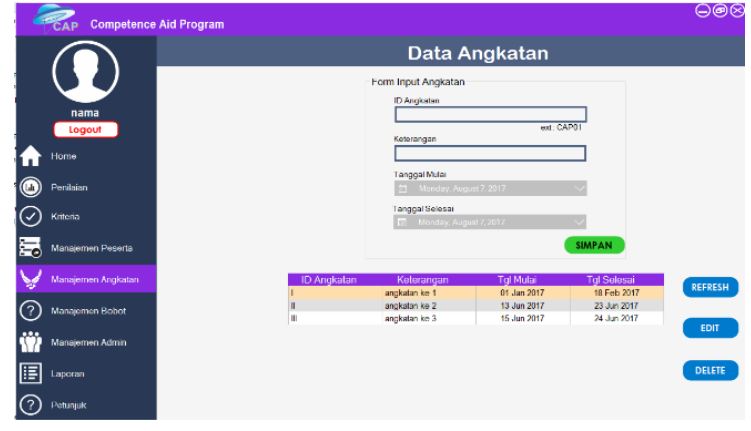

\section{Gambar 15. Tampilan Menu Manajemen Angkatan}

7) Tampilan Menu Manajemen Bobot

Tampilan menu manajemen bobot merupakan tampilan data data bobot. Bobot merupakan angka angka yang dijadikan sebagai acuan untuk memberikan nilai kepada setiap sub kriteria yang ada. Sub kriteria yang telah di inputkan akan diberikan nilai berdasarkan nilai di dalam data bobot ini. Menu ini merupakan master data bobot yang berisi data data bobot dimana dalam tampilan ini admin dapat mengelola data data bobot, seperti menambah, mengedit dan menghapus data bobot

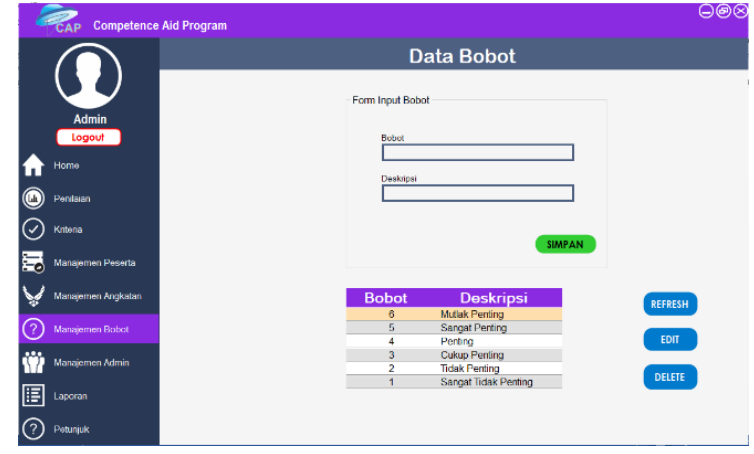

Gambar 16. Tampilan Menu Manajemen Bobot
8) Tampilan Menu Manajemen Admin

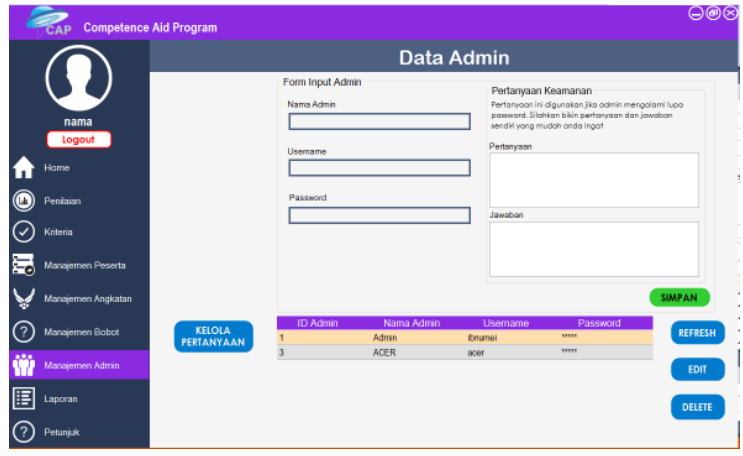

\section{Gambar 17. Tampilan Menu Manajemen Admin}

Tampilan menu manajemen admin merupakan tampilan yang berisi data data admin. Admin adalah orang yang diizinkan masuk kedalam sistem dan diizinkan untuk mengoperasikan sistem dan juga melakukan manipulasi data system

9) Tampilan Menu Laporan

Tampilan menu laporan merupakan tampilan yang berisi hasil perhitungan dari setiap peserta yang sudah diberikan nilai. Hasil perhitungan dihitung berdasarkan angkatan setiap peserta,

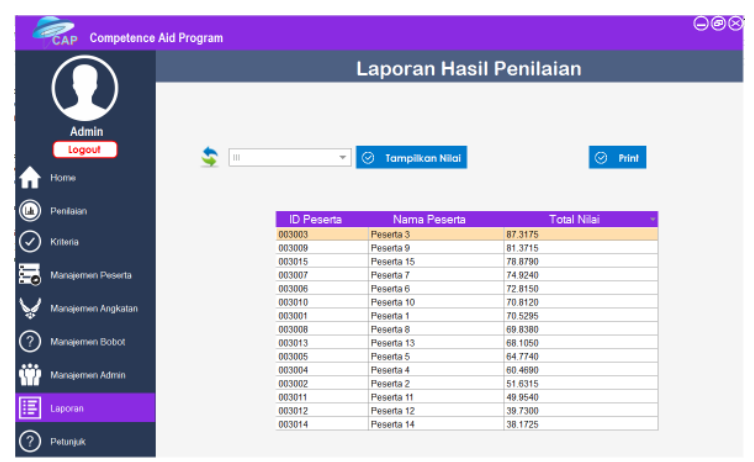

Gambar 18. Tampilan Menu Laporan 
10) Tampilan Menu Petunjuk

Tampilan menu petunjuk merupakan tampilan dari sedikit cara untuk pengoperasian system. Didalam menu disediakan petunjuk agar mudah dalam pengoperasian sistem

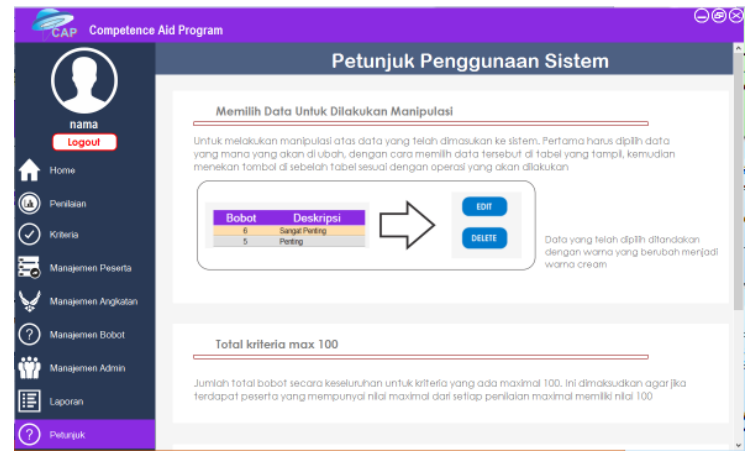

Gambar 19. Tampilan Menu Petunjuk

\section{KESIMPULAN}

Setelah menyelesaikan perancangan sistem pendukung keputusan penerimaan peserta competence aid program maka penulis menarik beberapa kesimpulan bahwa aplikasi ini dapat membantu untuk merekomendasikan peserta yang akan diterima. Aplikasi merekomendasikan peserta melalui perhitungan sehingga pengambilan keputusan lebih berdasar.

\section{REFERENSI}

Darmayuda, Ketut. (2014). Aplikasi Basis Data dengan Visual Basic. Net Studi kasus: Pengolahan Data Rekam Medis. Bandung: Informatika

Heny, Pratiwi.(2016). Buku Ajar Sistem Pendukung Keputusan. Yogyakarta: Deepublish
Hidayatullah, H \& K.K, Jauhari.(2014). Pemrograman Web. Bandung Informatika

Hirin, A.M. (2011). Belajar Tuntas VB.NET 2010. Jakarta. Prestasi Pustaka

Novian, Agung. (2004). Panduan Microsoft Visual Basic. Yogyakarta: Andi Offset.

Safaat, Nazruddin. (2014). Pemrograman aplikasi mobile berbasis android. Bandung: Informatika

Saputra, Agus. (2016). Aplikasi Inventory Berbasis Web. Cirebon: ASFA Solution

Shalahudin, M., \& A.S, Rosa. (2013). Rekayasa Perangkat Lunak Terstruktur dan Berorientasi Objek. Bandung: Informatika.

Subagia, Anton. (2017). Membangun Aplikasi dengan CodeIgniter dan Database SQL Server. Elex Media Komputindo: Jakarta

Sutopo, Ariesto Hadi. (2007). Pemrograman Flash Dengan PHP dan MySQL. Yogyakarta : Graha ilmu.

Yakub. (2012). Pengantar Sistem Informasi. Yogyakarta: Graha Ilmu 